\title{
Mechanical and thermal characterization of tungsten particulate reinforced epoxy polymer composites
}

DOI:10.36909/jer.ICMMM.12389

\author{
Jenson Joseph. E*, Kiran A.K, K. Panneerselvam
}

Faculty*, Department of Mechanical Engineering, PG Scholar, Production \& Industrial Engineering, SCMS School of Engineering and Technology, Ernakulam, Kerala, Faculty, Production Engineering Department, National Institute of Technology, Tiruchirappalli, Tamil Nadu, India.

*Email: jenson@scmsgroup.org; Corresponding Author.

\begin{abstract}
Polymer matrix composites find a wide range of industrial applications due to its unique properties like lightweight, improved strength and the properties could also be tailored to suit specific applications. In this present work, a new class of polymer matrix composites with epoxy resin as matrix and tungsten metal particles as fillers were developed. The influence of the addition of tungsten fillers on mechanical and thermal properties of the composites has been investigated. The composites are fabricated by hand lay-up method and the specimens containing tungsten particle content by $1 \%, 3 \%, 5 \%, 7 \%$ and $9 \%$ by weight were developed. The developed specimens were subjected to mechanical and thermal investigations. Mechanical behavior was analyzed by conducting a flexural test and hardness as per ASTM standards. Thermal behavior was analyzed by conducting Thermogravimetric analysis (TGA) and Differential Scanning Calorimetry (DSC) of the developed composites. The results show that the addition of $7 \mathrm{wt}$ \% filler has a higher value of flexural strength and hardness. Further addition of particulate fillers deteriorates the flexural strength and hardness due to agglomeration of filler content in the epoxy. Analysis by TGA and DSC shows that the thermal stability of composites is improved by increasing the addition of tungsten content in the epox.
\end{abstract}


Keywords: agglomeration; dispersion; polymer; thermograms.

\section{INTRODUCTION}

In recent years, technological advancement leading industries to adopt new advanced materials based on their functional performance. Reinforcement of particles in polymer matrix composites (PMC) may exhibit specific properties like thermal conductivity, dielectric constants and ductility, scratch resistance, wear and strength properties, impact performance and compressive strength. (Xu et al., 2001).

Epoxy is a thermoset polymer that can withstand higher-order loading conditions due to the formation of the cross-linked structure after it is cured. Among the thermoset materials, epoxy is the most popular choice as it is suitable to adhere strongly with a wide range of reinforcements. Reinforcements such as graphite, fibers, and metal powders can improve the tribological properties of epoxy composites up to great extent (Ji et al., 2014).

Several authors developed numerous composites based on epoxy resin. Jalali et al., investigated the electromagnetic shielding property of metallic nanoparticles reinforced epoxy composites by incorporating cobalt, iron, nickel and iron oxide and found that iron particles of $50 \mathrm{~nm}$ could able to produce the optimum level of reflectivity and absorptivity (Jalali et al.,2011). Visconti et al., developed an epoxy-based composite by reinforcing powders of silica and tungsten carbide in hand layup technique and reported that the incorporation of silica and tungsten carbide in epoxy could be able to improve wear characteristics of composites (Visconti et al., 2001). Srivastava et al., evaluated the mechanical properties of epoxy composite while reinforcing Copper and Aluminum in epoxy using hand layup method and revealed that the compressive strength and coefficient of friction values increased with addition of aluminum and Copper fillers (Srivastava et al., 2015). Martin et al., examined the mechanical properties of epoxy reinforced Nickel and Aluminium reinforced composite for application in structural energetic materials and reported improved strength on addition of nano aluminium particles 
(Martin et al., 2007). Ji et al., examined tribological behavior of foamed copper reinforced epoxy-matrix polymer and reported that the friction coefficients increased when foamed copper content is increased (Ji et al., 2014).

Zunjarrao et al., evaluated the fracture properties of epoxy reinforced aluminum particle composites and reported that particles of nanometer size showed higher fracture toughness values than micro meter-sized particle reinforced composite (Zunjarrao et al., 2006). Rosso et al., reported the influence of silica on Epoxy which is mixed by sol-gel process and found that silica-nanoparticles improved the toughness and stiffness of epoxy resin (Rosso et al., 2006). The incorporation of particular fillers enhances the thermal and mechanical properties of the polymer composites. Also, only very few metal fillers are used to develop polymer composites. Application of numerous metal fillers on the mechanical and thermal behavior of epoxy resin composites needed to be investigated. Among the research in metallic particulate composites, work published with tungsten fillers was found to be inadequate.

In this study, tungsten metal fillers are reinforced into epoxy resin matrix and composites are developed. The effect of tungsten particles on the thermal and mechanical properties of the epoxy composite has been investigated.

\section{MATERIALS AND METHODS}

The composites were fabricated using HW 153 Epoxy resin along with its hardener HV953 supplied by Sigma Aldrich, Bangalore. Epoxy resin and hardener were mixed with a predetermined ratio of 1:10. The particle filler used is tungsten metal particles of an average size of 6-micrometer was purchased from Sigma Aldrich, Bangalore. The composites were fabricated by hand lay-up methods. Samples containing tungsten particles by $1 \%, 3 \%, 5 \%$, $7 \%$ and $9 \%$ by weight were fabricated. The specimens were cut from the sheets as per the ASTM standards. The sample coding is shown in Table1. 
Table 1 Sample coding

\begin{tabular}{|c|l|}
\hline Sample Code & \multicolumn{1}{|c|}{ Description } \\
\hline ERP W00 & Pure Epoxy resin \\
\hline ERP W01 & Epoxy resin composite with 1wt. \% of W \\
\hline ERP W03 & Epoxy resin composite with 3wt. \% of W \\
\hline ERP W05 & Epoxy resin composite with 5wt. \% of W \\
\hline ERP W07 & Epoxy resin composite with 7wt. \% of W \\
\hline ERP W09 & Epoxy resin composite with 9wt. \% of W \\
\hline
\end{tabular}

\section{TESTING AND CHARACTERIZATION}

The mechanical behavior of the composites is studied by conducting the flexural test and hardness. The thermal behavior of the specimen is tested by conducting TGA and DSC analysis.

\section{Flexural Test}

The flexural test was performed on Tinius Olsen H50kl UTM which has a maximum load capacity of $50 \mathrm{kN}$. A three-point bending test was performed to study the flexural property of composite. The crosshead speed was maintained at $5 \mathrm{~mm} / \mathrm{min}$ and samples were cut as per ASTM D790 standards. Five specimens have been examined and their average values have been recorded.

\section{Hardness Test}

Shore Durometer hardness is performed to obtain the hardness of samples. Durometer tests the depth of the indentation in the material caused by a given geometric presser foot's specified force. The depth of indentation is noted for 5 trails and their average value is noted. All experiments are performed as per the ASTM D2240 standards.

\section{Thermo-Gravimetric Analysis}

TGA of the specimen was tested using NETZSCH model STA 449F3 TG analyzer. The test was performed as per ASTM E1131 standards. The specimen of $10 \mathrm{~g}$ weight is loaded in the aluminum crucible and heated at $10^{\circ} \mathrm{C} / \mathrm{min}$.

\section{Differential Scanning Calorimetry}


DSC analysis was performed in NETZSCH model STA 449F3DSC instrument. Samples of $10 \mathrm{~g}$ were heated at $10^{\circ} \mathrm{C} / \mathrm{min}$ ranging from $30^{\circ} \mathrm{C}$ to $220^{\circ} \mathrm{C}$ in aluminum crucible.

\section{RESULTS AND DISCUSSIONS}

\section{Flexural Test}

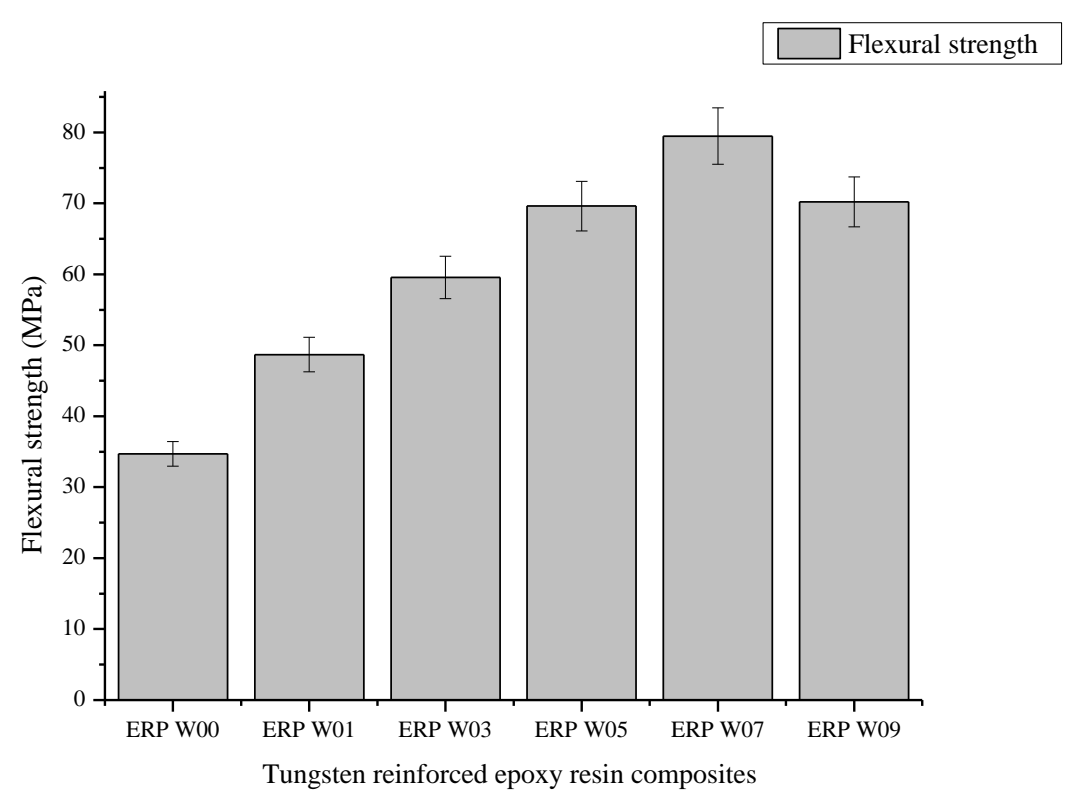

Figure 1 Flexural strength Vs Concentration of Tungsten

Figure 1 depicts the flexural strength of developed composites as a function of varying weight percentages of tungsten particles. The flexural strength of the composites increases gradually upto the addition of $7 \mathrm{wt} . \%$ of tungsten. With further increases in the concentration of tungsten above 7 wt. \% decreases the flexural strength. An increase in flexural properties is attributed to the uniform distribution of tungsten particles in the epoxy resin matrix. To study the dispersion of tungsten particles, samples were subjected to the Scanning electron microscope (SEM) analysis. SEM reveals the uniform distribution of tungsten fillers in samples with $7 \mathrm{wt}$. $\%$ of tungsten particles as show $\mathrm{n}$ in Figure 2a. Uniform distribution improves the adhesion of filler and matrix material which ultimately increases the flexural properties of the developed composites. The decrease in flexural strength is due to the agglomeration of tungsten fillers in the specimen with 9 wt. \% of tungsten particles as shown in Figure $2 \mathrm{~b}$. These agglomerated particles act as stress raisers which will ultimately decrease the flexural strength of the composites. 


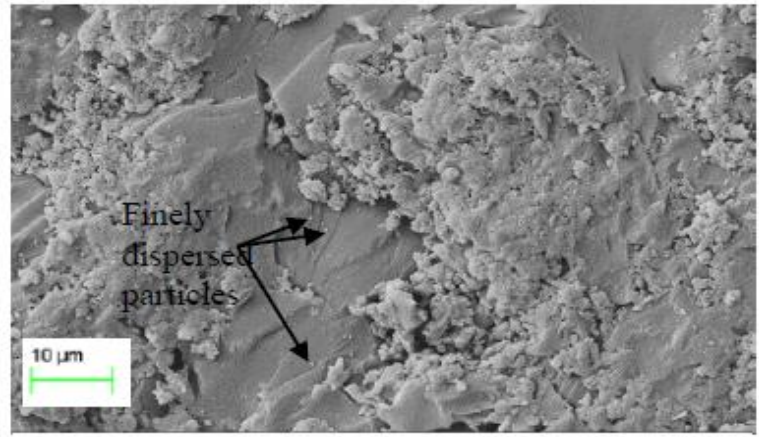

(a)

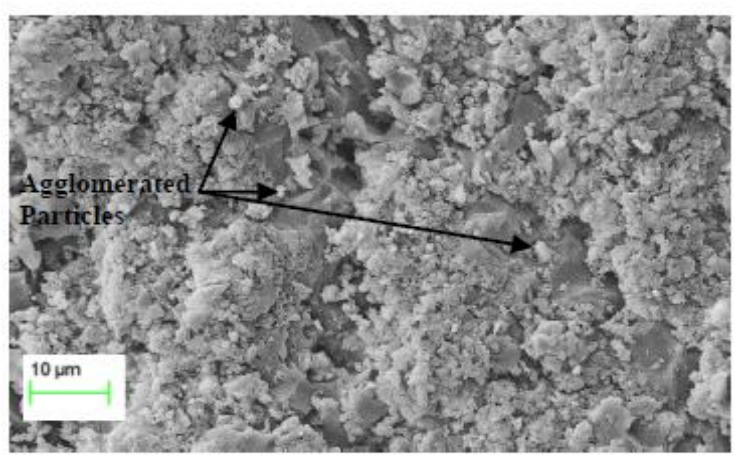

(b)

Figure 2 SEM micrograph of a) ERP W07 composites b) EPR W09 composites

\section{Hardness Test}

Figure 3 illustrates the hardness of composite samples with an increase in tungsten content. The hardness of the samples were improved till the addition of tungsten particles up to $7 \mathrm{wt}$. \% and increasing the tungsten beyond $7 \mathrm{wt} . \%$, the hardness was found to be decreased. The hardness of the sample depends on its ability to resist the change in shape permanently when the load is

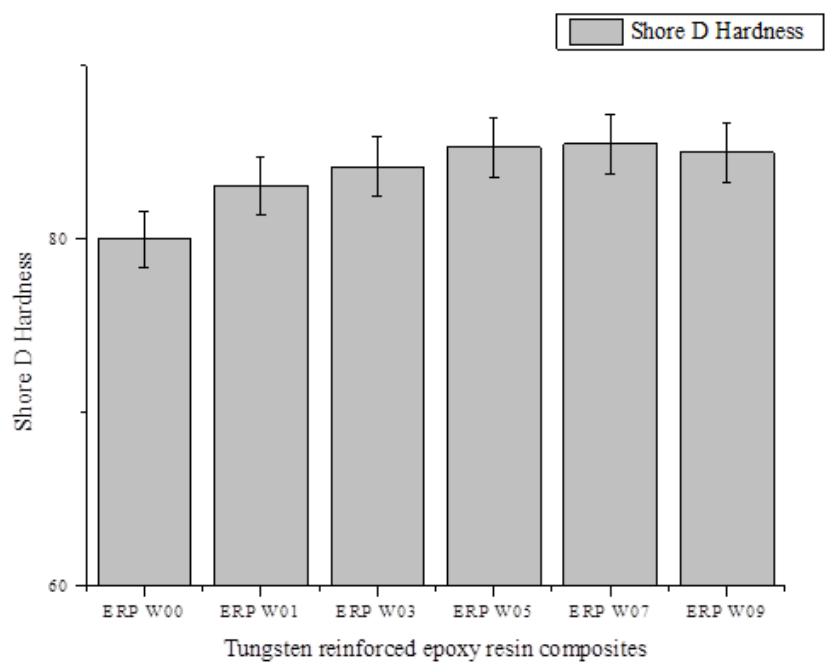

Figure 3.

Hardness of the Epoxy/tungsten composites

Shore D

applied to it. The increase in Hardness is due to the improved interfacial adhesion between the matrix and tungsten reinforcement which is due to the uniform distribution of tungsten particles.Beyond $7 \mathrm{wt} \%$ of tungsten, the hardness of the material is decreased. This can be 
attributed to two reasons. The addition of tungsten beyond $7 \mathrm{wt} \%$ made the composite more brittle. This brittle nature of composite could lead to stress risers developing an affinity towards crack growth. Also, agglomeration of particles at higher concentrations could enhance the void formation and decrease the interfacial adhesion.

\section{Thermogravimetric Analysis}

The TGA thermogram is depicted in Figure 4. Decomposition temperatures $\left(T_{d}\right)$ of composites, at 5\% mass degradation $\left(\mathrm{T}_{5 \%}\right)$, and 50\% mass degradation were noted $\left(\mathrm{T}_{50 \%}\right) . \quad \mathrm{T}_{5 \%}$ for $\mathrm{ERP}$ W00 occurs at $277^{\circ} \mathrm{C}$ and for ERP W09, T $5 \%$ occurs at $323^{\circ} \mathrm{C}$. The degradation temperature of composites shows an improvement of $46^{\circ} \mathrm{C}$ with the addition of $9 \mathrm{wt} . \%$ of tungsten partiulates, which is a very

high

improvement

thermal

of

composites.

Whereas $\mathrm{T}_{50 \%}$

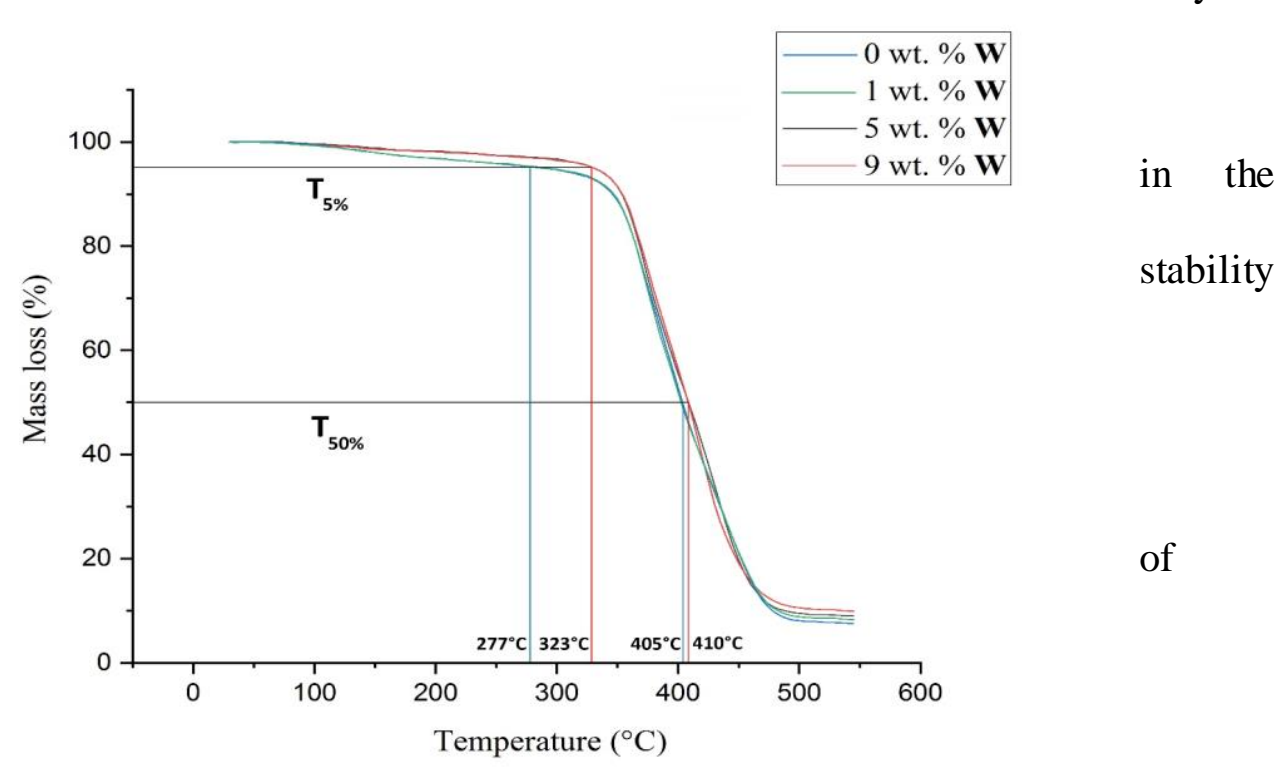


Figure 4 TGA Thermogram of Epoxy/tungsten composites

ERPW00 has a degradation temperature of $405^{\circ} \mathrm{C}$ and for ERP W09 the degradation temperature has been improved to $410^{\circ} \mathrm{C}$, which is also a significant improvement. Also, the char residue remaining at the end of decomposition improved from $7.58 \%$ for ERP W00 to 9.89\% for ERP W09 samples. The char residue improves with the increase in addition of tungsten. The improvement in decomposition temperature and char residue signifies the enhancement of

thermal stability of manufactured composites with the addition of tungsten particulate content.

\section{Differential Scanning Calorimetry}

DSC thermograms of the manufactured composites are displayed in Figure 5. From the thermograms, it can be noted that initially, the composite had undergone an endothermic reaction

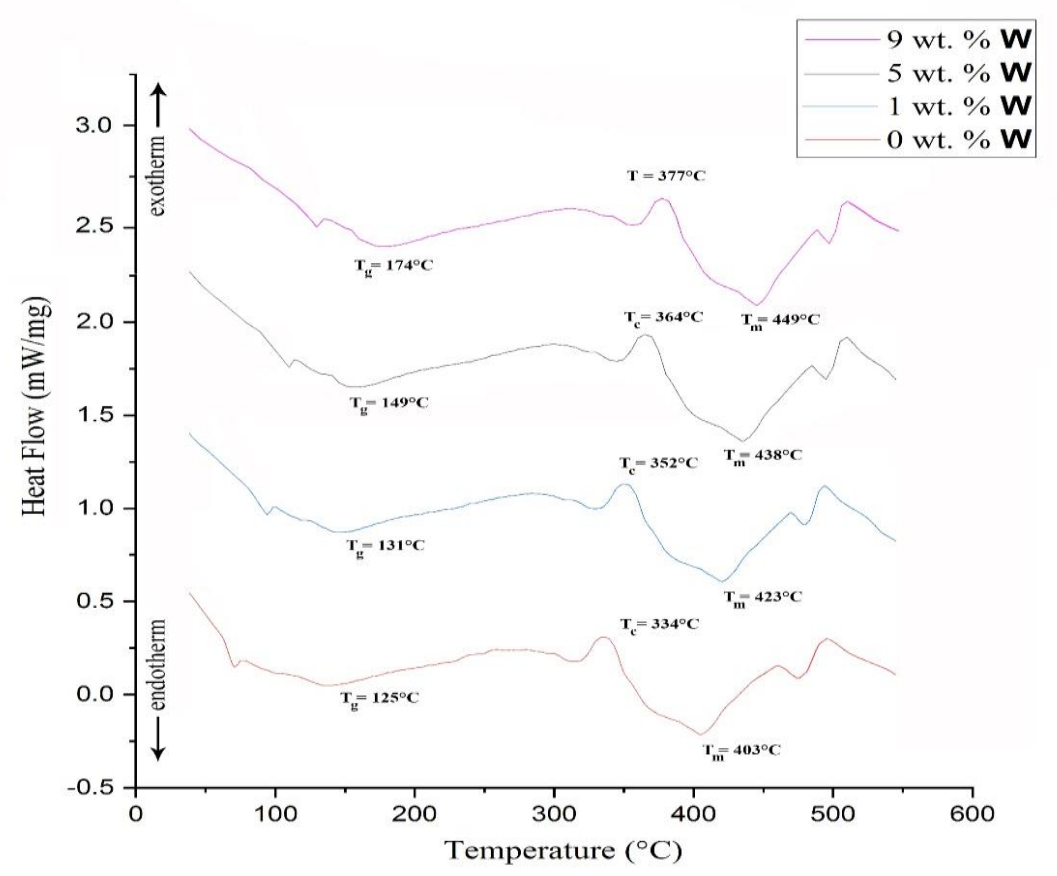

Figure 5 DSC thermogram of Epoxy/tungsten composites 
and the graph moved in a downward direction. The moisture content present in the composite leads to an endothermic dip where the composite receives heat from the source. The endothermic peak appeared at the first is attributed to the softening point of epoxy resin. The curve further goes into another dip which is the glass transition $\left(\mathrm{T}_{\mathrm{g}}\right)$ temperature of the developed composite. At this point, changes in chain mobility occur which will reflect in the mechanical properties of the material. The material will undergo a transition from elastic behavior to a brittle state. The transition does not occur at a certain specific point rather than at a range of temperatures. The temperature obtained from the middle point of the slope is taken as $\mathrm{T}_{\mathrm{g}}$ of material. The mobility of polymer chains increases above the glass transition temperature. When the temperature goes above $T_{g}$ chains have enough energy to form specific ordered arrangements and undergo an exothermic reaction. At this process, heat is liberated to the surroundings from the material and can be said as the crystallization process. This can be identified as the highest peak in the DSC thermogram. The temperature obtained from the corresponding peak is called crystallization temperature $\left(\mathrm{T}_{\mathrm{c}}\right)$. As it is an exothermic process, less amount of heat is required to maintain the temperature of the sample and reference pan. So, the heat flow towards the sample shows a decreasing profile in the thermogram. After the crystallization process, the material will start to absorb the heat and undergoes the melting process. The average kinetic energy of chains does not increase during this stage and the energy absorbed during this period is used to melt crystalline regions in the material. The melting point is the lowest dip in the DSC thermogram and the temperature corresponding to the dip represents the melting point (Tm) of material. The heat supplied at this process is the latent heat of melting. Beyond the melting process, the material undergoes thermal degradation and is represented as degradation temperature $\left(\mathrm{T}_{\mathrm{d}}\right)$. All the polymeric materials will undergo the transitions, glass transition, crystallization and melting. Pure amorphous polymeric materials only undergo glass transition and on the other hand, crystalline polymers undergo 
both amorphous and crystalline domains. The glass transition temperature of ERPW00 improved from $125^{\circ} \mathrm{C}$ to $174^{\circ} \mathrm{C}$ with the inclusion of $9 \mathrm{wt} . \%$ of tungsten particles. The crystallization temperature of the composites is also seen to increase from $334^{\circ} \mathrm{C}$ to $377^{\circ} \mathrm{C}$ with the addition of $9 \mathrm{wt} . \%$ of tungsten particulates. Incorporation of 9 wt. $\%$ of tungsten increased the melting temperature of the composites from $403^{\circ} \mathrm{C}$ to $449^{\circ} \mathrm{C}$, which is an indication of the significant improvement in the thermal property. The thermal behavior of the composites is thus enhanced by which the inclusion of tungsten fillers in the epoxy resin matrix.

\section{CONCLUSION}

Tungsten particles are successfully reinforced into the matrix of epoxy resin and composites are fabricated. The inclusion of tungsten particles could enhance the mechanical behavior of composites. Flexural test reveals that the maximum flexural strength obtained for composite with 7 wt. \% of tungsten with an improvement of $124 \%$. Shore D hardness shows that the maximum hardness obtained for composite with 7 wt. $\%$ of tungsten with $85 \%$ improvement and beyond this concentration, it is decreased. Thermogravimetric analysis reveals that the thermal stability of the prepared composites increased with the increase in concentration of tungsten particles. Thermal transition systems of epoxy/tungsten composites were analysed in the study. Crystallisation temperature $\left(\mathrm{T}_{\mathrm{c}}\right)$, melting temperature $\left(\mathrm{T}_{\mathrm{m}}\right)$ and glass transition temperature $\left(\mathrm{T}_{\mathrm{g}}\right)$ were determined from DSC analysis. Results showed that the thermal properties of the composites have been enhanced with the increase in tungsten particle concentration. The prepared composite can be used for high-temperature applications.

\section{FUTURE SCOPE}

This work can be extended to the possibilities of this particular material for tribological applications. Friction and wear characteristics of the material can be determined by evaluating the tribological properties. The concentration of reinforcement and matrix utilized in this composite can be changed for further studies in hybrid materials. 


\section{REFERENCES}

Bera, T., Acharya, S., \& Mishra, P. 2018. Synthesis, mechanical and thermal properties of carbon black/epoxy composites. International Journal Of Engineering, Science And Technology. 10(4):12.

Bigg, D., 1987. Mechanical properties of particulate filled polymers. Polymer Composites, 8(2). 115-122.

Cheang, P., \& Khor, K. 2003. Effect of particulate morphology on the tensile behavior of polymer-hydroxyapatite composites. Materials Science And Engineering: A. 345(1-2):47-54.

Deng, S., Ye, L. \& Friedrich, K., 2007. Fracture behaviours of epoxy nanocomposites with nano-silica at low and elevated temperatures. Journal of Materials Science. 42(8):27662774.

Fu, S., Feng, X., Lauke, B. and Mai, Y. 2008. Effects of particle size, particle/matrix interface adhesion and particle loading on mechanical properties of particulate-polymer composites. Composites Part B: Engineering. 39(6).933-961.

G. Marković, M. Marinović-Cincović, V. Jovanović, S. Samaržija-Jovanović \& J. Budinski-Simendić. 2015. Polymer characterization (II). Polymer science: research advances, practical applications and educational aspects. 397-403.

Goyal, V., \& Balandin, A. (2012). Thermal properties of the hybrid graphene-metal nanomicro-composites : Applications in thermal interface materials. Applied Physics Letters. 100(7). 073113.

Goyanes, S., Rubiolo, G., Marzocca, A., Salgueiro, W., Somoza, A., Consolati, G., \& Mondragon, I. 2003. Yield and internal stresses in aluminum filled epoxy resin. A compression test and positron annihilation analysis. Polymer. 44(11):3193-3199.

Gu, H., Ma, C., Gu, J., Guo, J., Yan, X., Huang, J., Zhang, Q. and Guo, Z. 2016. An overview of multifunctional epoxy nanocomposites. Journal of Materials Chemistry C. 
4(25):5890-5906.

Hussain, M., Oku, Y., Nakahira, A. \& Niihara, K., 1996. Effects of wet ball-milling on particle dispersion and mechanical properties of particulate epoxy composites. Materials Letters. 26(3).177-184.

Irez, A., Bayraktar, E., \& Miskioglu, I. 2017. Mechanical Characterization of Epoxy Scrap Rubber Based Composites Reinforced with Alumina Fibers. Mechanics Of Composite And Multi-Functional Materials. 6:59-70.

Jalali, M., Dauterstedt, S., Michaud, A. \& Wuthrich, R. 2011. Electromagnetic shielding of polymer-matrix composites with metallic nanoparticles. Composites Part B: Engineering, 42(6):1420-1426.

Ji, K., Xu, Y., Zhang, J., Chen, J. \& Dai, Z. 2014. Foamed-metal-reinforced composites: Tribological behavior of foamed copper filled with epoxy-matrix polymer. Materials \& Design, 61:109-116.

Jumahat, A., Soutis, C., Mahmud, J. \& Ahmad, N., 2012. Compressive Properties of Nanoclay/Epoxy Nanocomposites. Procedia Engineering. 41: 1607-1613.

Khan, M., Lehmann, D., Heinrich, G., Gohs, U. \& Franke, R. 2009. Structure-property effects on mechanical, friction and wear properties of electron modified PTFE filled EPDM composite. Express Polymer Letters. 3(1). 39-48.

Kiran, M., Govindaraju, H. \& Jayaraju, T. 2018. Evaluation of Mechanical Properties of Glass Fiber Reinforced Epoxy Polymer Composites with Alumina. Titanium dioxide and Silicon Carbide Fillers. Materials Today: Proceedings, 5(10):22355-22361.

Kumar, V., RamKumar, J., Aravindan, S., Malhotra, S., Vijai, K., \& Shukla, M. 2009. Fabrication and characterization of ABS nano composite reinforced by nano sized alumina particulates. International Journal Of Plastics Technology. 13(2):133-149.

MacCallum, J. (1985). Thermogravimetric analysis of polymers for assessing thermal 
degradation. Thermochimica Acta. 96(2): 275-281.

Martin, M., Hanagud, S. \& Thadhani, N. 2007. Mechanical behavior of nickel+aluminum powder-reinforced epoxy composites. Materials Science and Engineering: A, 443(12):209-218.

McGrath, L., Parnas, R., King, S., Schroeder, J., Fischer, D. \& Lenhart, J., 2008. Investigation of the thermal, mechanical, and fracture properties of alumina-epoxy composites. Polymer, 49(4): 999-1014.

Nagavally, R. 2017. Composite Materials - History, Types, Fabrication Techniques, Advantages, and Applications. International Journal of Mechanical and Production Engineering (IJMPE). 9(5):82-87.

Nayak, R., Tarkes, D., \& Satapathy, A. 2010. A computational and experimental investigation on thermal conductivity of particle reinforced epoxy composites. Computational Materials Science. 48(3):576-581.

Phua, J., Teh, P., Ghani, S., \& Yeoh, C. 2016. Influence of thermoplastic spacer on the mechanical, electrical, and thermal properties of carbon black filled epoxy adhesives. Polymers For Advanced Technologies. 28(3). 345-352.

Rodgers, R., Mahfuz, H., Rangari, V., Chisholm, N., \& Jeelani, S. 2005. Infusion of SiC Nanoparticles Into SC-15 Epoxy: An Investigation of Thermal and Mechanical Response. Macromolecular Materials And Engineering. 290(5). 423-429.

Rosso, P., Ye, L., Friedrich, K. \& Sprenger, S. 2006. A toughened epoxy resin by silica nanoparticle reinforcement. Journal of Applied Polymer Science, 100(3):1849-1855.

Singla, M., \& Chawla, V. 2010. Mechanical Properties of Epoxy Resin - Fly Ash Composite. Journal Of Minerals And Materials Characterization And Engineering. 09(03):199-210.

Srivastava, V. \& Verma, A. 2015. Mechanical Behaviour of Copper and Aluminium 
Particles Reinforced Epoxy Resin Composites. American Journal of Materials Science, 5(4):84-89.

Tavman, I. 1996. Thermal and mechanical properties of aluminum powder-filled highdensity polyethylene composites. Journal of Applied Polymer Science. 62: 2161-2167.

Thostenson, E., \& Chou, T. (2006). Processing-structure-multi-functional property relationship in carbon nanotube/epoxy composites. Carbon. 44(14).3022-3029.

U. Nirmal, J. Hashim \& S.T.W. Lau 2011. Testing methods in tribology of polymeric composites. International Journal of Mechanical and Materials Engineering, 6(3):367-373.

Verma, A., \& Srivastava, V.K. 2015. Mechanical Behavior of Metal Particles reinforced Polymer Matrix Composites. International Journal of Mechanical And Production Engineering, 3(6):104-108.

Visconti, I., Langella, A. \& Durante, M. 2001. The Wear Behaviour of Composite Materials with Epoxy Matrix Filled with Hard Powder. Applied Composite Materials, 8(3): 179-189.

Y. Xu, D. D. L. Chung \& C. Mroz. 2001. Thermally conducting aluminum nitride polymer matrix composites. Composite Part A: Applied Science and Manufacturing, 32(12):17491757.

Zhang, P., Li, Q. \& Xuan, Y. 2014. Thermal contact resistance of epoxy composites incorporated with nano-copper particles and the multi-walled carbon nanotubes. Composites Part A: Applied Science and Manufacturing, 57:1-7.

Zhou, W., \& Yu, D. 2010. Thermal and dielectric properties of the aluminum particle/epoxy resin composites. Journal Of Applied Polymer Science, 118(6):3156-3166.

Zunjarrao, S. \& Singh, R. 2006. Characterization of the fracture behavior of epoxy reinforced with nanometer and micrometer sized aluminum particles. Composites Science and Technology, 66(13):2296-2305. 